\title{
On the genus Stephostethus LeConte, 1878 (Coleoptera: Latridiidae: Latridiinae) from Taiwan, with descriptions of two new species
}

\author{
Yu-Hsiang $\mathrm{HO}^{1}$, Wolfgang H. RÜCKER ${ }^{2}$ \& Mei-Ling $\mathrm{CHAN}^{3, *}$ \\ ${ }^{1}$ Department of Entomology, National Chung Hsing University, Taichung, Taiwan. \\ ${ }^{2}$ Von-Ebner-Eschenbach-Straße 12, 56567 Neuwied, Germany. \\ ${ }^{3}$ Division of Biology, National Museum of Natural Science, Taichung, Taiwan. \\ *Corresponding author: meiling@mail.nmns.edu.tw \\ 1Email: b123b44@gmail.com \\ 2Email:w_ruecker@wruecker.de \\ ${ }^{1}$ urn:lsid:zoobank.org:author:2FB86166-A7DF-4D90-BB66-5467E550A30C \\ ${ }^{2}$ urn:1sid:zoobank.org:author:6B60B62B-69D9-48C6-B291-74CDACEAB601 \\ ${ }^{3}$ urn:1sid:zoobank.org:author:3432B9A4-FE0C-4E46-B719-95FA9EF28B49
}

\begin{abstract}
The genus Stephostethus LeConte, 1878 of minute brown scavenger beetles (Coleoptera: Latridiidae: Latridiinae) is recorded from Taiwan for the first time, which extends the southernmost boundary of this genus in the Palaearctic realm. Two new species, S. taiwanus sp. nov. and S. yuanfengensis sp. nov., and one new record, S. chinensis (Reitter, 1877), are described in this study. A taxonomic key to the three species of this genus in Taiwan is also provided. The distributions, habitats and collecting methods of these three species, as well as the structure of the genital segments of this genus are discussed.
\end{abstract}

Keywords. Latridiidae, Stephostethus, taxonomy, new species, Taiwan.

Ho Y.-H., Rücker W.H. \& Chan M.-L. 2021. On the genus Stephostethus LeConte, 1878 (Coleoptera: Latridiidae: Latridiinae) from Taiwan, with descriptions of two new species. European Journal of Taxonomy 735: 1-14. https://doi.org/10.5852/ejt.2021.735.1235

\section{Introduction}

The genus Stephostethus LeConte, 1878, consisting of 37 species worldwide, belongs to the subfamily Latridiinae Erichson, 1842. Most of the species are distributed in the Palaearctic and Nearctic realms, and seem to be restricted to temperate regions; in Asia there are records from areas such as China, Nepal and the mountainous areas of India (Rücker 2015, 2018, 2020).

LeConte (1878) described this genus based on the following characters: "the prosternum extends only a short distance behind the coxae, and is enclosed by the epimera, which coalesce on the median line as in Rhynchophora; the front coxae are also conical, prominent and contiguous. The antennae are slender and longer than the head and thorax, as in the true Lathridii with costate prothorax". Within the genus, Muona (1983) and Rücker $(2018,2020)$ mentioned that the teeth on male tibiae and the structure of 
genital segments are the best diagnostic characters for species identification, and the aedeagus is often weakly chitinized, limiting its use as a diagnostic character. However, the genital segments were termed " $7^{\text {th }}$ tergite" in Muona (1983) and "fusion of last tergite and sternite" in Rücker $(2018,2020)$. Sen Gupta (1976) redefined the genus Stephostethus, added three species from India, and subsequently revised this genus and described nine new species from India (Sen Gupta 1983). Rücker (2004) described a new species from China, and since then, no further Stephostethus species have been added.

To date, in Taiwan, only three genera of Latridiinae have been recorded (Chan \& Lee 2016; Ho et al. 2019). Herein, we report a new record of the genus Stephostethus from Taiwan, add three species of Stephostethus from Taiwan, including one new record and two new species, and provide an identification key for all species in the region. We have also investigated the abdominal segments of the genus and attempt to determine the appropriate terminology for the genital segments.

\section{Material and methods}

Specimens were collected and preserved dry for morphological observation. Dissections of male genitalia were performed. The abdomen was removed, soaked in a high concentration $\mathrm{KOH}$ solution for at least ten minutes (depending on the specimen condition), and was then cleaned in distilled water. The abdomen sternite, tergite and aedeagus were removed for further examination under a stereo microscope. Photographs of adults were taken with a Canon EOS 650D camera equipped with a Canon MP-E65 f/2.8 1-5 $\times$ macro lens, and photographs of genital segments were taken with a Canon EOS 650D camera attached to a Zeiss Axioskop 2 microscope. All photographs were subsequently focus stacked with Helicon Focus software. Figures of male tibiae and the structure of genital segments were drawn using Adobe Illustrator CS6. The terminology used herein follows Ho et al. (2019) and Rücker $(2018,2020)$.

\section{Depositories}

NCHU = National Chung Hsing University, Taichung, Taiwan

NMNS = National Museum of Natural Science, Taichung, Taiwan

PCHO = Private collection of Yu-Hsiang Ho, Taichung, Taiwan

TARI = Taiwan Agricultural Research Institute, Taichung, Taiwan

WRCN = Private collection of Wolfgang Rücker, Neuwied, Germany

\section{Results}

Class Insecta Linnaeus, 1758

Order Coleoptera Linnaeus, 1758

Family Latridiidae Erichson, 1842

Subfamily Latridiinae Erichson, 1842

Genus Stephostethus LeConte, 1878

\section{Type species}

Lathridius liratus LeConte, 1863.

\section{Diagnosis}

Species of Stephostethus LeConte can be distinguished from related genera in Taiwan by the following characters: mandible with single apical tooth and inner margin smooth. Eyes well developed. Pronotum square, sides more or less parallel, with two carinae on disc; prosternal process short, narrow and not extending to apex, epimera not separated by prosternal process and meeting each other on median line. The genital segments are defined as the abdominal $8^{\text {th }}-10^{\text {th }}$ segments herein (Figs 13-14). 


\section{Key to the species of Stephostethus LeConte, 1878 from Taiwan}

1. Pronotum longer than wide, $7^{\text {th }}$ interstriae of elytra weakly carinate, mid tibia of male with a distinct tooth ..... S. yuanfengensis sp. nov.

- Pronotum wider than long, $7^{\text {th }}$ interstriae of elytra strongly carinate, mid tibia of male without a distinct tooth

2. Anterior end of $7^{\text {th }}$ interstriae of elytra protruding at front, male hind tibia with three distinct teeth. S. chinensis (Reitter, 1877)

- Anterior end of $7^{\text {th }}$ interstriae of elytra not protruding at front, male hind tibia with four indistinct teeth (sometimes barely visible)

S. taiwanus sp. nov.

Stephostethus taiwanus sp. nov. urn:1sid:zoobank.org:act:35987EB7-6F55-4EB3-B5C0-4DAC0F3D049C

Figs $1-3,12$

\section{Diagnosis}

This species is closely related to Stephostethus chinensis (Reitter, 1877), but can be distinguished by the $7^{\text {th }}$ interstriae, which are less protruding at the front, the structure of the genital segments of the male, and the characters of the teeth on the male tibiae. Stephostethus taiwanus sp. nov. has four indistinct teeth on the hind tibia, whereas $S$. chinensis has three distinct teeth on the hind tibia.

\section{Etymology}

The specific epithet, taiwanus, is named after its country of discovery, Taiwan.

\section{Material examined}

\section{Holotype}

TAIWAN • ${ }^{\text {; }}$; Nantou, Yuanfeng; 8 Dec. 2005-3 Jan. 2006; C.S. Lin and W.T. Yang leg.; Malaise trap; NMNS ENT 7408-4.

\section{Paratypes}

TAIWAN - 1 J; Taipei, Wulai, Happen; 9 Dec. 1985; C.C. Chiang leg.; sweeping net; NMNS ENT 2493-33 • 1 ; ; Miaoli, Taian; 19 Dec.1989; K.W. Huang leg.; sweeping; NMNS ENT 1113-219 • 1 ô; Taichung City, Shei-Pa National Park; $24.38329^{\circ}$ N, $121.28631^{\circ}$ E; 2 Apr. 2010; W.B. Yeh leg.; sweeping shrub; WRCN • 1 ते; Taichung City, Shei-Pa National Park; $24.38985^{\circ}$ N, 121.27618 ${ }^{\circ}$ E; 9 Feb. 2011; W.B. Yeh leg.; sweeping shrub; WRCN • $1{ }^{\Uparrow}$; Nantou, Yuanfeng; 7 Mar.-13 Apr. 2006; C.S. Lin and W.T. Yang leg.; Malaise trap; NMNS ENT 7421-68 • 1 §̊; same collection data as for preceding; 9 May-6 Jun. 2006; NMNS ENT 7421-1099 • 1 ; ; same collection data as for preceding; 3 May-7 Jun. 2005; NMNS ENT 7388-390 • 1 ô; same collection data as for preceding; 8 Nov.-8 Dec. 2005; NMNS ENT 7393-1096•1 ð’; Nantou Hsien, Tsuifeng; 2300 m a.s.1.; 8 Nov. 1981; S.C. Lin and W.S. Tang leg.; TARI • 1 đ̇; Nantou County, Xinyi, Tatajia; 27 Mar. 2018; H.T. Yeh leg.; in Picea forest; PCHO • 1 ơ; Chiayi Hsien, Alishan; $2400 \mathrm{~m}$ a.s.1.; 17-20 Aug. 1982; K.C. Chou and C.C. Pan leg.; TARI 1 ô; Tainan City, Sinhua Forest Area, 15 Feb. 2020; Y.H. Ho leg.; beating dead dry branches; PCHO 1 O ; Taitung, Peinan, Panchiu Station, 16 Dec. 2004-17 Feb. 2005; C.S. Lin and W.T. Yang leg.; Malaise trap; NMNS ENT 5871-99.

\section{Description}

LeNGTH. 1.82-2.05 mm.

WIDTH. $0.87-0.95 \mathrm{~mm}$. 


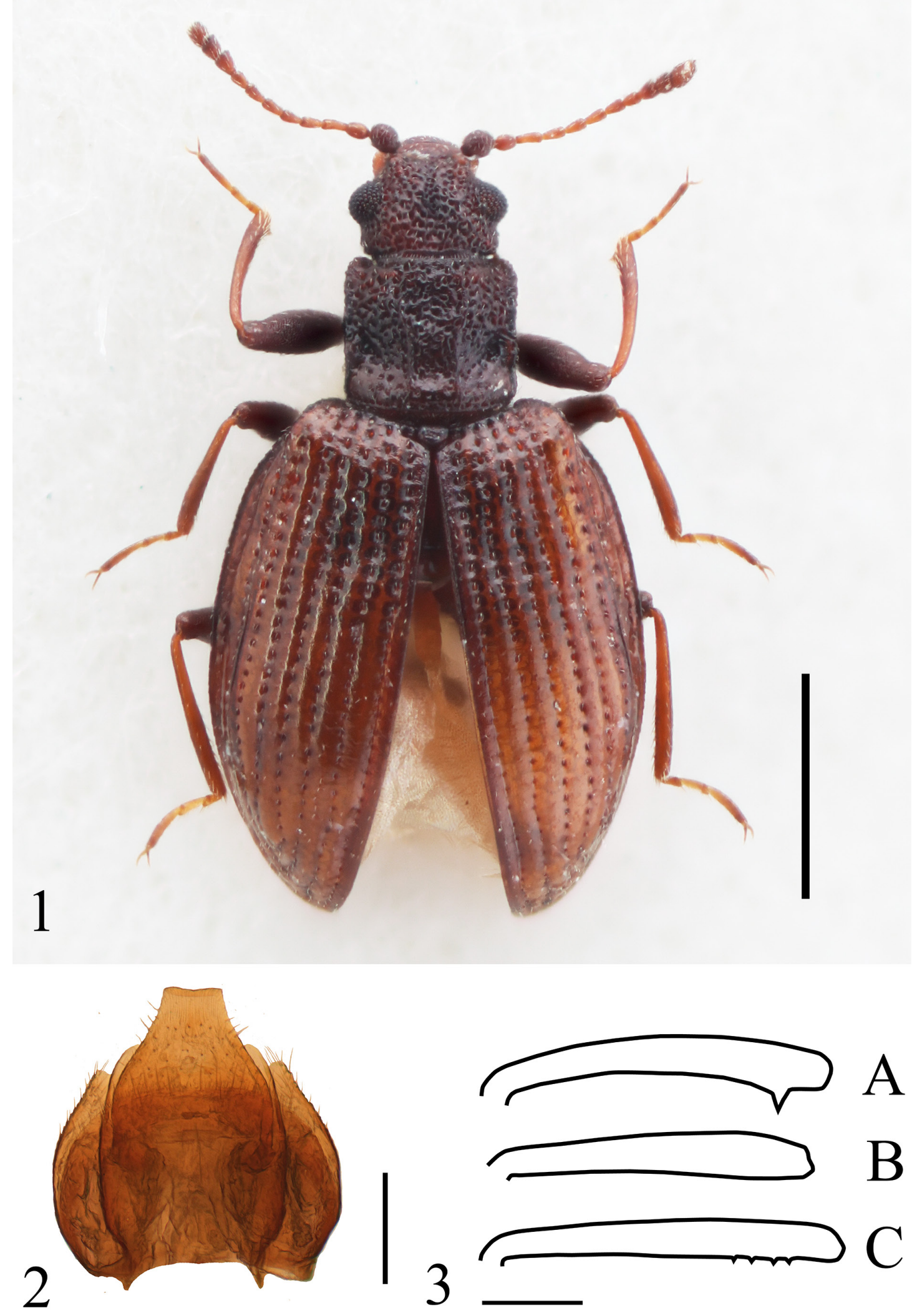

Figs 1-3. Stephostethus taiwanus sp. nov. paratype (TARI). 1. Habitus, dorsal view. 2. Male genital segments, dorsal view. 3. Male tibiae, $\mathrm{A}=$ protibia, $\mathrm{B}=$ midtibia, $\mathrm{C}=$ hindtibia. Scale bars: $1=0.5 \mathrm{~mm}$; $2-3=0.1 \mathrm{~mm}$. 
CoLour. General body yellowish brown to dark brown, with tibiae, tarsi and antennae light brown.

HEAD. Slightly longer than wide, width to length ratio $1.00: 1.11$; strongly punctate, clypeus narrower than head, with short setae. Eyes well developed, with more than 20 facets; temple narrower than eye, about half length of eye, hind angle of temple with or without a sharp tooth. Antennae with 11 segments, $3^{\text {rd }}$ segment slightly shorter than $4^{\text {th }}$ segment, $4^{\text {th }}$ to $8^{\text {th }}$ segment same in length; apical three segments clubbed.

Pronotum. Almost as long as wide, width to length ratio 1.00:0.94; sides almost parallel, widest at anterior margin, narrowest at posterior one-third. Front angle barely protruding and bluntly rounded, posterior one-third with a pair of depressions. Surface irregularly and densely punctate, with a pair of carinae on disc. Sometimes covered with wax on lateral and ventral sides.

Elytra. Broadly oval, width to length ratio $1.00: 1.41$, broadest at middle, apex round. Depression on posterior one third indistinct. With eight punctate striae, $1^{\text {st }}$ striae complete, $2^{\text {nd }}$ striae connected with $7^{\text {th }}$ striae at posterior end, $3^{\text {rd }}$ striae connected with $6^{\text {th }}$ striae, $4^{\text {th }}$ striae connected with $5^{\text {th }}$ striae, $8^{\text {th }}$ striae incomplete. $5^{\text {th }}$ interstriae weakly carinate, $7^{\text {th }}$ interstriae weakly protruding at front, extending to middle. Sides weakly carinate. Scutellum broadly pentagonal, much wider than long.

Metasternum. Strongly convex, each side with fovea situated under mid coxa, and surrounded by radial striae, sometimes covered with wax on meso- and metasternum.

LEGs. Long and slender, covered with short setae on femora and tibiae. Male with one distinct tooth on anterior end of protibia and four indistinct teeth on anterior end of hind tibia, sometimes barely visible, mid tibia without any teeth; anterior end of protibia straight, apex expanded, mid and hind tibia straight.

MaLe Genitalia. Aedeagus weakly chitinized, long and slender, sides parallel, with apex sharp, curve at middle in lateral view. Genital segments weakly chitinized, with apical end truncate, broadest at base (Fig. 2).

\section{Distribution}

Taiwan (Fig. 12). Widely found in various altitude levels ranging from 100 to $2300 \mathrm{~m}$ a.s.l.

\section{Remarks}

This species is widely distributed in Taiwan, and partly overlaps with the range of $S$. yuanfengensis sp. nov. in central and southern Taiwan. So far, of the three species of Stephostethus LeConte in Taiwan, only S. taiwanus sp. nov. is found in northern Taiwan. Some of the specimens were collected by beating the dead dry branches in a broadleaf forest ( $100 \mathrm{~m}$ a.s.1.).

Stephostethus yuanfengensis sp. nov. urn:Isid:zoobank.org:act:4DE4DC6D-203D-4AEF-8978-CE3E204EE6BF

Figs 4-6, 10, 12

\section{Diagnosis}

This species is closely related to Stephostethus setosus Rücker, 2004 from China, but can be distinguished by the following characters: (1) hairs on elytra are shorter than those of S. setosus, (2) pronotum is more slender than that of S. setosus, and (3) structure of genital segments of male is different from that of S. setosus. In S. setosus, the apical end of the genital segments is sharper than in S. yuanfengensis sp. nov. 


\section{Etymology}

The specific epithet, yuanfengensis, is named after the type locality, Yuanfeng, in central Taiwan.

\section{Material examined}

\section{Holotype}

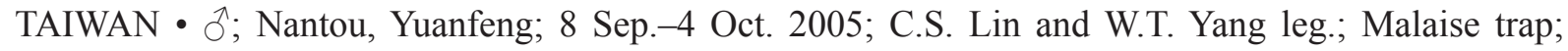
NMNS ENT 7393-180.

\section{Paratypes}

TAIWAN • 1 §̊; Miaoli, Taian; 19 Dec. 1989; K.W. Huang leg.; sweeping; NMNS ENT 1113-203 •

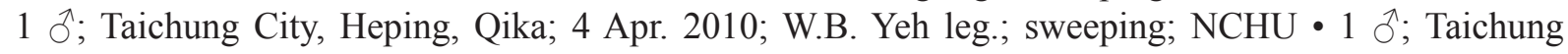
City, Heping, Qika; $24.387279^{\circ} \mathrm{N}, 121.284885^{\circ}$ E; 5 Apr. 2009; W.B. Yeh leg.; sweeping Miscanthus;

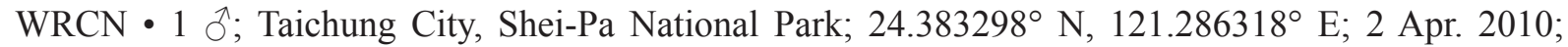
W.B. Yeh leg.; sweeping shrub; WRCN 11 ô; Nantou, Lienhuachih, Watersher n ${ }^{\circ} 3$; 1 Aug. -7 Sep. 2005; C.S. Lin and W.T. Yang leg.; Malaise trap; NMNS ENT 6773-89 • 1 §ै; Nantou, Jenai, Piluchi; 4 Dec. 1991; Y.C. Shiau leg.; sweeping net; NMNS • 1 §ै; Hualien Hsien, Tayuling; 2560 m a.s.l.; 9-16 Jun. 1980; K.S. Lin and B.H. Chen leg.; TARI • 1 गे; Nantou Hsien, Meifeng; 2150 m a.s.1.; 22 May 1982; L.Y. Chou leg.; TARI • 1 đ̃; Nantou Hsien, Meifeng; 2230 m a.s.l.; 10 May 1979; K.C. Chou leg.; TARI • 1 万; ; Nantou, Meifeng; 5 Jul.-2 Aug. 2005; C.S. Lin and W.T. Yang leg.; Malaise trap; NMNS ENT 7488-934 • 1 §; Nantou, Yunhaipaohsienso; 4 May 1992; W.T. Yang leg.; sweeping net; NMNS ENT 1447-1046• 2 $\widehat{\jmath}$; Nantou, Yuanfeng; 7 Mar.-13 Apr. 2006; C.S. Lin and W.T. Yang leg.; Malaise trap; NMNS ENT 7421-36, 7421-64 1 o ; same collection data as for preceding; 5 Mar.-16 Apr. 2003; NMNS ENT 6603-19 • 1 đ̧; same collection data as for preceding; 5 Mar.-7 Jun. 2005; NMNS ENT 7388-345 • 1 ऊ ; same collection data as for preceding; 8 Mar.-12 Apr. 2005; NMNS ENT 7388-22 • 1 ऊ; same collection data as for preceding; 13 Apr.-9 May 2008; NMNS ENT 7421-594 •

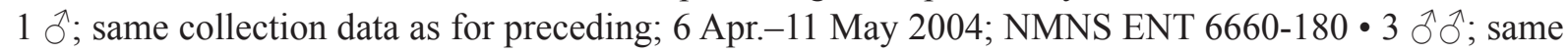
collection data as for preceding; 9 Apr.-19 May 1998; NMNS ENT 3113-127, 3113-161, 3113-188 •

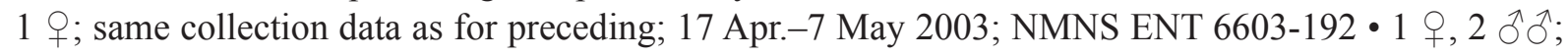
same collection data as for preceding; 9 May-6 Jun. 2006; NMNS ENT 7421-1098 (ㅇ), 7421-1094

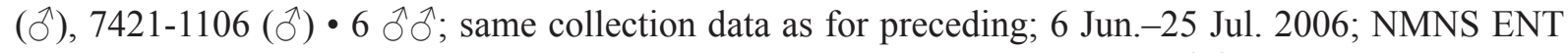

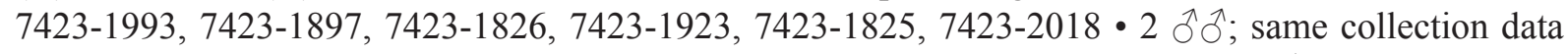
as for preceding; 25 Jul.-22 Aug. 2006; NMNS ENT 7423-3062, 7423-3119 • 1 ○; same collection

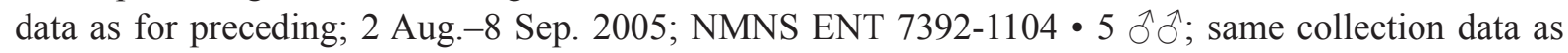
for preceding; 8 Sep.-4 Oct. 2005; NMNS ENT 7393-65, 7393-153, 7393-157, 7393-159, 7393-199 •

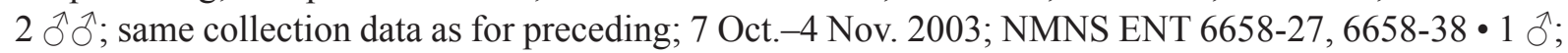
Nantou Hsien, Tsuifeng; 2300 m a.s.1.; 8 Nov. 1981; S.C. Lin and W.S. Tang leg.; TARI 1 q, 1 ऽ;; Nantou, Hsini, Patungkuan; 13-15 Jun. 1989; K.W. Huang; sweeping; NMNS ENT 460-463 (ð̋), $460-$ 466 (ㅇ) 1 ơ; Chiayi Hsien, Alishan; 2400 m a.s.1.; 5-9 Aug. 1981; L.Y. Chou and S.C. Lin leg.; TARI • 1 đ̃; Chiayi County, Alishan, Shishan race; 8 Mar. 2020; Y.H. Ho and P.Y. Shih leg.; PCHO • 1 o; Chiayi, Yu-shan West peak; 15 May 1991; C.C. Chiang leg.; sweeping and sucking; NMNS ENT 112746 - 4 ôं; Kaoshiang [Kaohsiung, mistyped] (TM12), Tengchih; 22-30 Dec. 2008; C.-T. Yao leg.; TARI • 1 ; Kaoshiang [Kaohsiung, mistyped] (MM2), Shihshan logging trail; 18-25 Feb. 2009; C.T. Yao leg.; TARI • 1 §’; Kaohsiung City, Taoyuan, Shishan logging trail; 8 Feb. 2020; C.T. Hsu leg.; beating; $\mathrm{PCHO} \bullet 1$ ऊ ; Pintung, Kuaiku Coffage; 21 May 1991; C.C. Chiang leg.; sweeping and sucking;

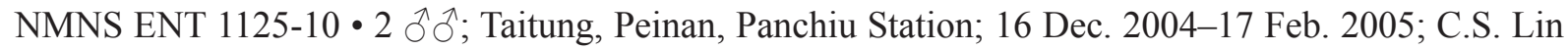
and W.T. Yang leg.; Malaise trap; NMNS ENT 5871-102, 5871-104.

\section{Description}

LeNGTH. $1.83-2.02 \mathrm{~mm}$. 


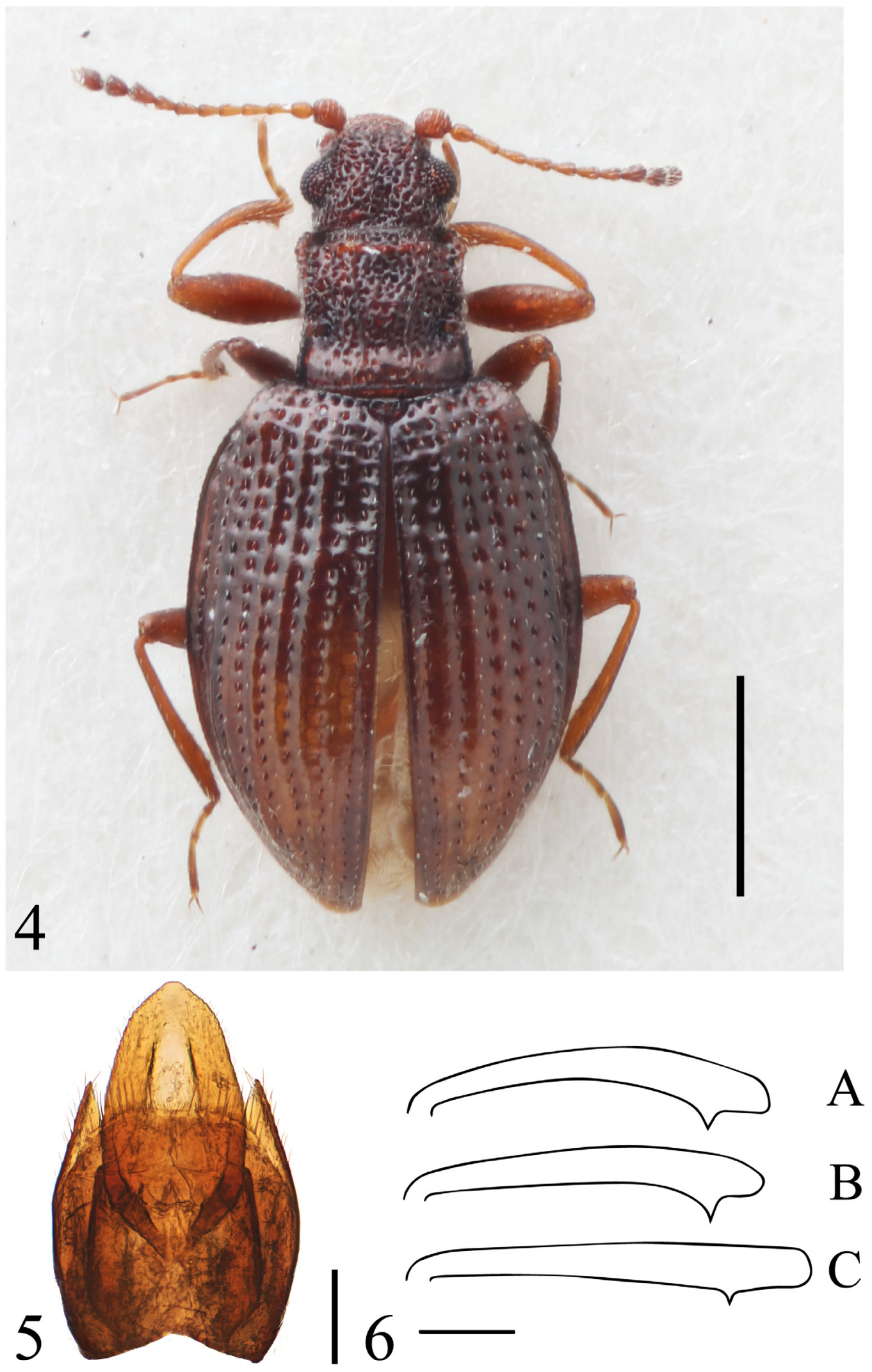

Figs 4-6. Stephostethus yuanfengensis sp. nov., holotype (NMNS ENT 1113-203) 4. Habitus, dorsal view. 5. Male genital segments, dorsal view. 6 . Male tibiae, $A=$ protibia, $B=$ midtibia, $C=$ hindtibia. Scale bars: $4=0.5 \mathrm{~mm} ; 5-6=0.1 \mathrm{~mm}$. 
WIDTH. 0.86-0.91 mm.

CoLour. General body colour light brown, with head and pronotum dark brown.

HEAD. Slightly longer than wide, width to length ratio $1.00: 1.20$, strongly punctate, clypeus narrower than head, with some short setae. Eyes strongly developed, with more than 20 facets; temple narrower than eye, about half length of eye, hind angle with or without a sharp tooth. Antennae 11-segmented, $3^{\text {rd }}$ segment slightly longer than $4^{\text {th }}$ segment, $5^{\text {th }}$ to $8^{\text {th }}$ segment same in length, apical three segments clubbed.

Pronotum. Slightly longer than wide, width to length ratio $1.00: 1.05$, widest at anterior margin, narrowest at anterior third. Sides carinate; front angle strongly protruded and bluntly rounded, posterior one-third with a pair of round depressions. Surface irregularly and densely punctate, with a pair of carinae on disc. Sometimes covered with wax on lateral and ventral sides.

ELYTRA. Broadly oval, width to length ratio $1.00: 1.40$, broadest at middle, apex round. Depression on posterior third indistinct. With eight punctate striae, $1^{\text {st }}$ striae complete, $2^{\text {nd }}$ striae connected with $7^{\text {th }}$ striae at posterior end of elytra, $3^{\text {rd }}$ striae connected with $6^{\text {th }}$ striae, $4^{\text {th }}$ striae connected with $5^{\text {th }}$ striae, $8^{\text {th }}$ striae incomplete. $5^{\text {th }}$ interstriae not carinate, $7^{\text {th }}$ interstriae weakly carinate, only extended to anterior one-fifth, slightly protruded. Scutellum broadly pentagonal.

Metasternum. Strongly convex, with fovea situated under mid coxa on each side and surrounded by radial striae. Sometimes covered with wax on meso- and metasternum.

LEGS. Long and slender, covered with short setae on femora and tibiae. Male with one distinct tooth on each anterior end of protibia, mid tibia and hind tibia; anterior end of protibia expanded and curved, mid tibia and hind tibia straight. Female without any teeth on tibia.

MALE GENITALIA. Aedeagus weakly chitinized, long and slender, sides parallel, weakly curved at middle, and straight at apex in lateral view. Genital segments long and slender, broadest at base, middle area less chitinized, apical end spear-shaped (Fig. 5).

\section{Distribution}

Central to southern Taiwan (Fig. 12). This species can be found in areas from low to high elevation (300-3518 m a.s.1.).

\section{Remarks}

From our records, S. yuanfengensis sp. nov. can be caught in Malaise traps in large numbers (ca 100 individuals at a time) at the type locality. Some of the specimens were collected by beating dry dead branches and damp leaves in an artificial red oak forest ( $2300 \mathrm{~m}$ a.s.1.) (Fig. 10).

\section{Stephostethus chinensis (Reitter, 1877)}

Figs 7-9, 11-14

Lathridius chinensis Reitter, 1877: 113.

Stephostethus chinensis - Rücker 2018: 172.

\section{Diagnosis}

Stephostethus chinensis (Reitter 1877) is similar to S. carinatus Sen Gupta, 1976 from India. However, the former species can be distinguished from the latter by the structure of the genital segments of the 
male, and the characters of the teeth on male tibiae, as S. carinatus has one tooth on the mid tibia, and $S$. chinensis has no teeth on the mid tibia.

\section{Material examined}

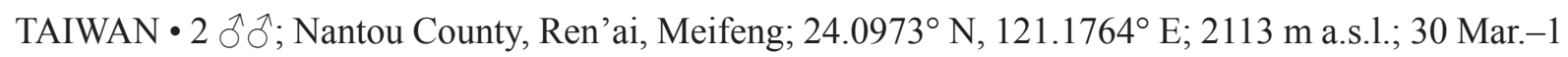
Apr. 2020; F.S. Hu and Y.J. Chen leg.; by flight interception trap; PCHO • 1 \%; Nantou, Meifeng; 3-15 Oct. 1990; C.K. Starr leg.; yellow pan trap; NMNS ENT 766-5 • 1 đ̊; Nantou, Jenai, Meifeng; 12 Nov.10 Dec. 2002; C.S. Lin and W.T. Yang leg.; Malaise trap; NMNS ENT 4913-1077 • 1 ○े; Kaoshiang [Kaohsiung, mistyped] (TM7), Tengchih; 9-18 Feb. 2009; C.T. Yao leg.; TARI • 1 क; Kaoshiang [Kaohsiung, mistyped] (TM3), Tengchih; 9-18 Feb. 2009; C.T. Yao leg.; TARI • 1 đ; Kaohsiung City, Taoyuan, Shishan logging trail; 8 Feb. 2020; C.T. Hsu leg.; beating; PCHO • 2 ठふぇ; Taitung Hsien, Chihpen; 17-18 Feb. 1982; L.Y. Chou and K.C. Chou leg.; TARI.

\section{Description}

LENGTH. 1.83-2.00 mm.

WIDTH. 0.86-0.97 mm.

CoLour. General body colour brown to dark brown, with legs and antennae yellowish brown.

HEAD. Slightly longer than wide, width to length ratio $1.00: 1.20$, surface strongly punctate, base of head depressed, clypeus narrower than head, covered with some short setae; temple narrower than eye, about half length of eye, with sharp hind angle. Antennae 11-segmented, second segment slightly shorter than third segment, apical three segments clubbed. Eyes strongly developed, with more than 20 facets. Sometimes covered with wax in ventral view.

Pronotum. Slightly wider than long, width to length ratio 1.00:0.95; sides almost parallel, widest at anterior margin, narrowest at posterior one-third. Front angle slightly protruded and bluntly rounded, anterior third with a pair of triangular depressions. Surface irregularly and densely punctate, with a pair of carinae on disc. Prosternum short, procoxa separated. Sometimes covered with wax in ventral and lateral views.

ELYTRA. Broadly oval, width to length ratio $1.00: 1.40$, broadest at middle, apex round. Posterior third depressed. With eight punctate striae, $1^{\text {st }}$ striae complete, $2^{\text {nd }}$ striae connected with $7^{\text {th }}$ striae at posterior end of elytra, $3^{\text {rd }}$ striae connected with $6^{\text {th }}$ striae, $4^{\text {th }}$ striae connected with $5^{\text {th }}$ striae, $8^{\text {th }}$ striae incomplete. $5^{\text {th }}$ interstriae weakly carinate, $7^{\text {th }}$ interstriae strongly protruding at front, and extended to middle, with short setae. Scutellum broadly pentagonal.

Metasternum. Strongly convex, with fovea situated under mid coxa on each side and surrounded by radial striae. Sometimes covered with wax on meso- and metasternum.

LEGS. Long and slender, covered with short setae on femora and tibiae. Tarsi 3-3-3, tarsomere 3 longer than 1 and 2 combined; arolium indistinct. Male protibia expanded and curved at apex, with one distinct tooth on anterior end; mid tibia straight, without any teeth; hind tibia straight, with three distinct teeth on anterior end. Female without any teeth on legs.

Male genitalia. Aedeagus weakly chitinized. Long and slender, sides parallel, sharp at apex; bent at anterior two fifths, and weakly curved at anterior fifth. Genital segments broad and short, broadest at base, apical end deeply concave with two rounded lobes (Fig. 8). 

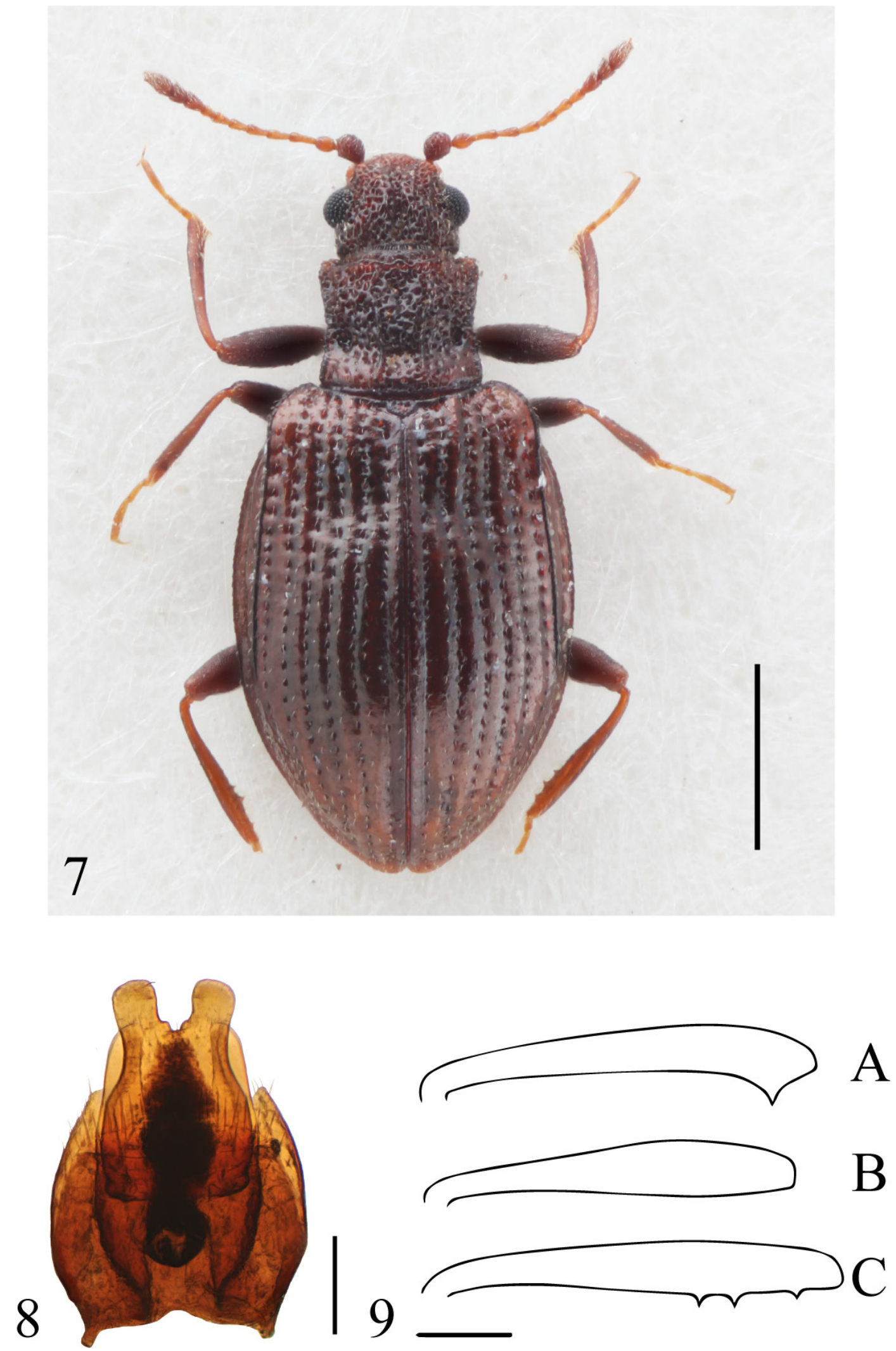

Figs 7-9. Stephostethus chinensis (Reitter, 1877) (TARI). 7. Habitus, dorsal view. 8. Male genital segments, dorsal view. 9. Male tibiae, $\mathrm{A}=$ protibia, $\mathrm{B}=$ midtibia, $\mathrm{C}=$ hindtibia. Scale bars: $7=0.5 \mathrm{~mm}$; $8-9=0.1 \mathrm{~mm}$. 


\section{Distribution}

This species is only known from Asia, including Eastern Siberia, China, Japan and Mongolia (Johnson 2007; Rücker 2018, 2020), and is new to Taiwan (Fig. 12). It is distributed in mid to southern Taiwan, and is widely recorded in various areas, ranging in altitude from 300 to $2300 \mathrm{~m}$ a.s.l.

\section{Remarks}

Stephostethus chinensis was recorded as a household pest in Japan (Tanaka \& Tahira 1995). However, we have never found this species in indoor environments in Taiwan. Some specimens of this species were collected by beating damp leaves in an artificial red oak forest ( $1700 \mathrm{~m}$ a.s.l.), and some were collected with flight interception traps in the forest (2113 m a.s.1.) (Fig. 11).

\section{Discussion}

The Palaearctic realm is the most species-rich area for Stephostethus, with 28 species, mostly distributed in the temperate regions (Johnson 2007). Within this realm, Northern India was formerly the southernmost extent of this genus (Sen Gupta 1983). Our discovery of new records of Stephostethus extended the boundary of this genus to Taiwan as the southernmost distributional extent in the Palaearctic realm.

Minute brown scavenger beetles (Coleoptera: Latridiidae) are mycetophagous and are frequently found in a variety of wet or damp forested habitats. The main collecting situations for Stephostethus in India
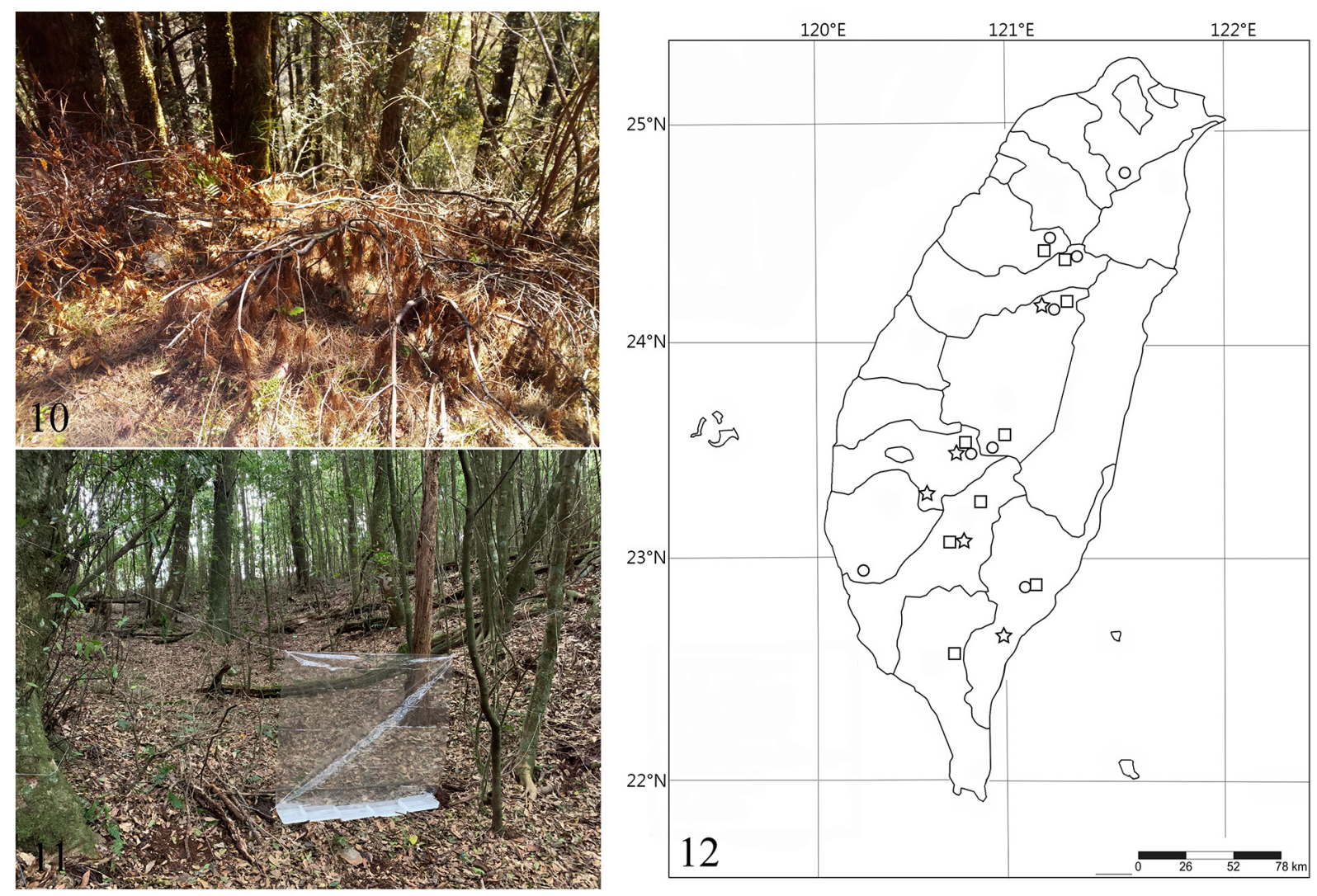

Figs 10-12. Habitat and distribution map of Stephostethus LeConte, 1878 in Taiwan. 10. Habitat of S. yuanfengensis sp. nov. 11. Habitat of S. chinensis (Reitter, 1877) (photo courtesy of F.S. Hu). 12. Distribution map of species of Stephostethus in Taiwan: S. taiwanus sp. nov. (open circle), S. yuanfengensis sp. nov. (open square), S. chinensis (open star). 
are from foliage, haystacks, bark, grass and grass roots (Sen Gupta 1976, 1983). Sen Gupta (1983) also mentioned that the genus seemed to be associated with decaying plants. This observation is consistent with the first author's field experiences in Taiwan; the species of Stephostethus can be collected by beating dead branches, especially dead, dry branches. However, most of our specimens were collected by Malaise and flight interception traps, which also collect other latridiid species. No specimens of Stephostethus were collected with a light trap during our field investigations, and none were found during specimen examination in various institutes, which suggests that species of this genus are not attracted to light.

Our detailed examination during this study revealed that Stephostethus has ten abdominal segments, a finding missed by previous investigators. The term " $7^{\text {th }}$ tergite" used in Muona (1983) and the "fusion of last tergite and sternite" in Rücker $(2018,2020)$ are actually the $8^{\text {th }}-10^{\text {th }}$ abdominal segments, in terms of genital segments. These errors may result from overlooking the segmentation of the genital segments or the $1^{\text {st }}$ tergite. The genital segments are usually retracted inside the $7^{\text {th }}$ tergite and sternite, but in dead specimens they are sometimes exposed. The structure of genital segments of Stephostethus, especially the shape of $10^{\text {th }}$ tergite, varies between species but is stable within species, suggesting that genital segment structure can serve as a reliable character for species identification.

Although we have described the current distribution of Stephostethus in Taiwan, it is clear that much remains to be learned. Further research is warranted to better understand the morphology, phylogeny, distribution and ecology of these beetles.

\section{Acknowledgements}

We would like to express our gratitude to Prof. Wen-Bin Yeh, Mr Fang-Shuo Hu and Mr Chi-Ting Hsu (Department of Entomology, Chung Hsing University) for their kindness in collecting and offering specimens for our study. Dr Jing-Fu Tsai (Division of Biology, National Museum of Natural Science)

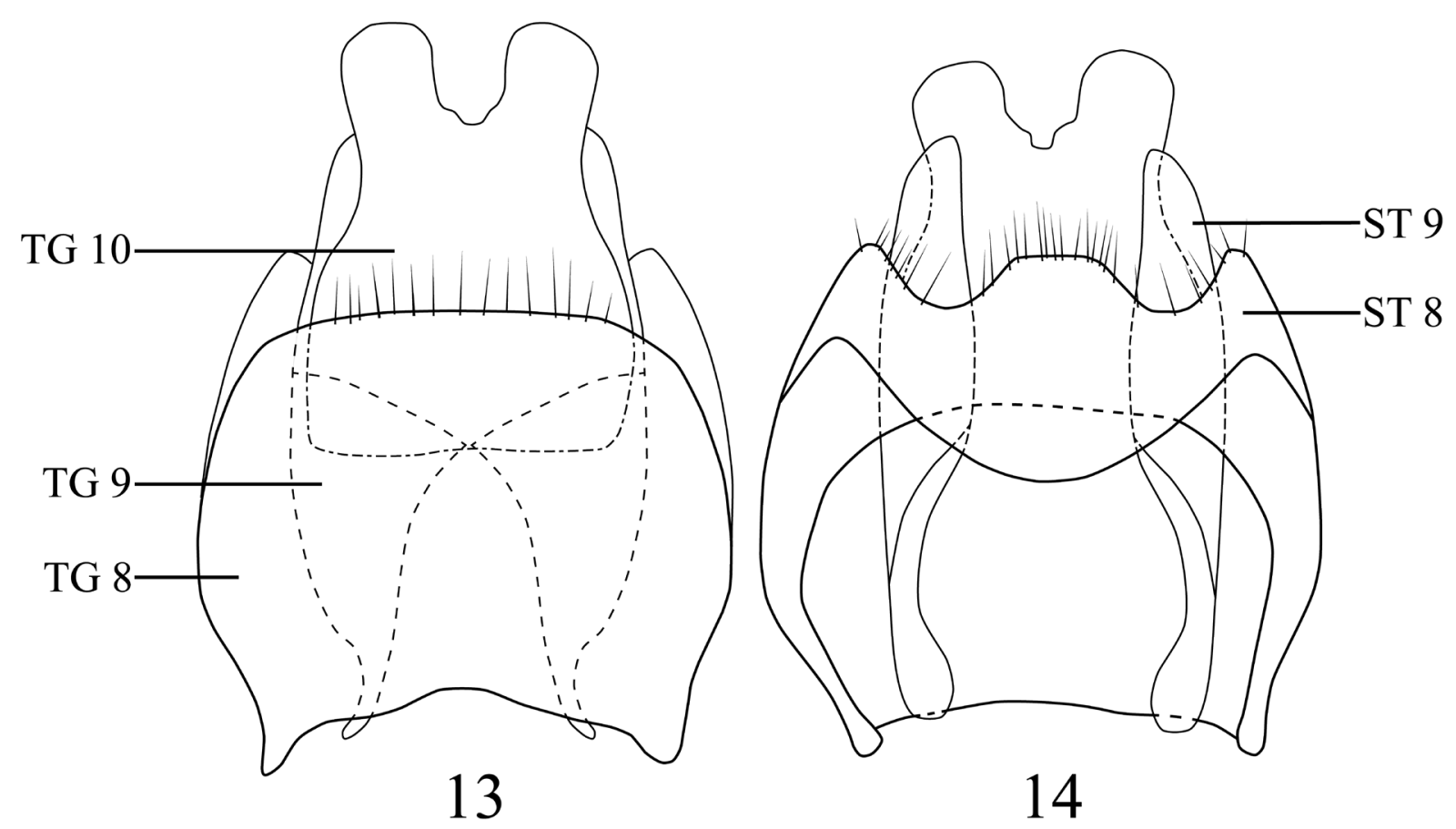

Figs 13-14. Structure of genital segments of Stephostethus chinensis (Reitter, 1877). 13. Dorsal view. 14. Ventral view. Abbreviations: $\mathrm{TG}=$ tergite; $\mathrm{ST}=$ sternite. 
and Dr Chi-Feng Lee (Division of Applied Zoology, Taiwan Agricultural Research Institute) are thanked for kindly loaning important specimens to us. Special thanks also to Dr Ling-Hsiu Liao (Department of Entomology, University of Illinois at Urbana-Champaign) and Dr David L. Evans for the manuscript editing and improvement of the English. Permission to collect specimens in the national park was authorized by Shei-Pa National Park (Permission Number 1001000534). This study was supported by the Ministry of Science and Technology (Most-107-2515-S-178 -002 -MY3).

\section{References}

Chan M.L. \& Lee K.H. 2016. A new record of Latridiidae (Coleoptera), Eufallia seminivea (Motschulsky), from Taiwan, with notes on its occurrence. Formosan Entomologist 36: 84-93. https://doi.org/10.6662/TESFE.2016010

Ho Y.H., Chan M.L. \& Rücker W.H. 2019. Dienerella (Dienerella) beloni (Reitter): a newly recorded species of Latridiidae (Coleoptera) in Taiwan. Formosan Entomologist 39: 46-52. https://doi.org/10.6662/TESFE.201905_39(2).001

Johnson C. 2007. Latridiidae. In: Löbl I. \& Smetana A. (eds) Catalogue of Palaearctic Coleoptera, Vol. 4. Elateroidea, Derodontoidea, Bostrichoidea, Lymexyloidea, Cleroidea and Cucujoidea: 74-80. Apollo Books, Stenstrup, Denmark.

LeConte J.L. 1878. Description of new species. In: Hubbard H.G. \& Schwarz E.A. (eds) The Coleoptera of Michigan. Proceedings of the American Philosophical Society 17: 593-669.

Muona J. 1983. Taxonomic notes on the genus Stephostethus LeConte (Coleoptera, Latridiidae). Notulae Entomologicae 63: 14-16.

Reitter E. 1877. Neue Coleoptera aus Japan. Deutsche Entomologische Zeitschrift 21: 109-116.

Rücker W.H. 2004. Stephostethus setosus sp. nov., eine neue Latridiidae aus China (Coleoptera: Latridiidae). Latridiidae 2: 6-9.

Rücker W.H. 2015. Checklist Latridiidae \& Merophysiidae of the World. Latridiidae \& Merophysiinae 10: $1-18$.

Rücker W.H. 2018. Latridiidae und Merophysiidae der West-Paläarktis. Published by the author, Neuwied.

Rücker W.H. 2020. Latridiidae und Merophysiidae der West-Paläarktis. $2^{\text {nd }}$ Edition. Published by the author, Neuwied.

Sen Gupta T. 1976. Lathridiinae (Coleoptera: Lathridiidae) from India. Oriental Insects 10: 113-135.

Sen Gupta T. 1983. Revision of the Indian Stephostethus LeConte (Coleoptera, Lathridiidae). Entomologica Brasiliensia 8: 342-368.

Tanaka K. \& Tahira Y. 1995. Several lathridiid beetles new to or little known from Japan. House and Household Insect Pests 17 (1): 37-40. [In Japanese.]

Manuscript received: 28 August 2020

Manuscript accepted: 17 January 2021

Published on: 15 February 2021

Topic editor: Nesrine Akkari

Section editor: Max Barclay

Desk editor: Kristiaan Hoedemakers 
Printed versions of all papers are also deposited in the libraries of the institutes that are members of the EJT consortium: Muséum national d'histoire naturelle, Paris, France; Meise Botanic Garden, Belgium; Royal Museum for Central Africa, Tervuren, Belgium; Royal Belgian Institute of Natural Sciences, Brussels, Belgium; Natural History Museum of Denmark, Copenhagen, Denmark; Naturalis Biodiversity Center, Leiden, the Netherlands; Museo Nacional de Ciencias Naturales-CSIC, Madrid, Spain; Real Jardín Botánico de Madrid CSIC, Spain; Zoological Research Museum Alexander Koenig, Bonn, Germany; National Museum, Prague, Czech Republic. 